\title{
Development and evaluation of a self-efficacy instrument for Japanese sleep apnea patients receiving continuous positive airway pressure treatment
}

This article was published in the following Dove Press journal:

Nature and Science of Sleep

29 January 2015

Number of times this article has been viewed

\section{Ayako Saito' \\ Shigeko Kojima² \\ Fumihiko Sasaki ${ }^{3}$ \\ Masamichi Hayashi ${ }^{4}$ \\ Yuki Mieno ${ }^{4}$ \\ Hiroki Sakakibara ${ }^{5}$ \\ Shuji Hashimoto'}

'Department of Hygiene, School of Medicine, Fujita Health University,

Toyoake, Japan; ${ }^{2}$ Department of Rehabilitation, Faculty of Health Sciences, Nihon Fukushi University, Handa, Japan; ${ }^{3}$ SDB Research Laboratory, Takaoka Clinic, Nagoya, Japan; ${ }^{4}$ Department of Internal Medicine, Division of Respiratory Medicine and Clinical Allergy, Fujita Health University, Toyoake, Japan;

${ }^{5}$ Tokushige Kokyuki Clinic,

Nagoya, Japan
Correspondence: Ayako Saito Department of Hygiene, School of Medicine, Fujita Health University, I-98, Dengakugakubo, Kutsukake-cho, Toyoake, Aichi 470-I 192, Japan

Tel/fax +8I 562932456

Email a-saito@fujita-hu.ac.jp
Abstract: The purpose of this study was to develop and evaluate a self-efficacy instrument for Japanese obstructive sleep apnea (OSA) patients treated with continuous positive airway pressure (CPAP). Analyzed subjects were 653 Japanese OSA patients (619 males and 34 females) treated with CPAP at a sleep laboratory in a respiratory clinic in a Japanese city. Based on Bandura's social cognitive theory, the CPAP Self-Efficacy Questionnaire for Sleep Apnea in Japanese (CSESA-J) was developed by a focus group of experts, using a group interview of OSA patients for the items of two previous self-efficacy scales for Western sleep apnea patients receiving CPAP treatment. CSESA-J has two subscales, one for self-efficacy and the other for outcome expectancy, and consists of a total of 15 items. Content validity was confirmed by the focus group. Confirmatory factor analysis showed that the factor loadings of self-efficacy and outcome expectancy were $0.47-0.76$ and $0.41-0.92$, respectively, for the corresponding items. CSESA-J had a significant but weak positive association with the General Self-Efficacy Scale, and a strong positive association with "Self-efficacy scale on health behavior in patients with chronic disease." Cronbach's alpha coefficient was 0.85 for the self-efficacy subscale and 0.89 for the outcome expectancy subscale. The intraclass correlation coefficient using data from the first and second measurements with CSESA-J for a subset of 130 subjects was 0.93 for the selfefficacy and outcome expectancy subscales. These results support CSESA-J as a reliable and valid instrument for measuring the self-efficacy of Japanese OSA patients treated with CPAP. Further studies are warranted to confirm validity for female OSA patients and generalizability.

Keywords: scale development, obstructive sleep apnea, continuous positive airway pressure, social cognitive theory

\section{Introduction}

Obstructive sleep apnea (OSA) is an important cause of medical morbidity and mortality. ${ }^{1-4}$ Continuous positive airway pressure (CPAP) is a primary treatment for OSA. CPAP use for moderate and severe OSA patients is effective in reducing uncomfortable symptoms, improving quality of life, and extending the vital prognosis. ${ }^{5-8}$ Nevertheless, many patients started on CPAP do not use it correctly or stop using it after a short period. ${ }^{9-13}$

Self-efficacy has been pointed out as a psychological factor associated with adherence to CPAP treatment. ${ }^{14,15}$ Self-efficacy in Bandura's social cognitive theory refers to a person's belief that he or she is able to exercise some measure of control over challenging environmental demands by taking adaptive action. ${ }^{16-19}$ The General Self-Efficacy Scale (GSES) for general attitudes has been developed and translated into several languages. ${ }^{20}$ In addition, a country-specific scale has been developed. ${ }^{21}$ Meanwhile, 
two scales for sleep apnea patients treated with CPAP have also been developed: the Self-Efficacy Measure for Sleep Apnea (SEMSA) and the Social Cognitive Theory (SCT) scale. ${ }^{14,15}$ Both scales were originally intended for Western populations and, so far, a measurement targeting Asians, including Japanese, has not been developed. In planning the present study, we reviewed both scales and debated whether or not their Japanese-translated versions would be suitable for Japanese OSA patients treated with CPAP. We decided that several of the items would not be suitable for Japanese OSA patients treated with CPAP and that it would be appropriate to develop a new instrument for use with Japanese patients. Our judgments are discussed in detail below.

The purpose of this study was to develop and evaluate a new self-efficacy instrument for Japanese OSA patients treated with CPAP, hereafter referred to as the CPAP Self-Efficacy Questionnaire for Sleep Apnea in Japanese (CSESA-J).

\section{Methods}

\section{Subjects}

Our subjects were Japanese OSA patients treated with CPAP at the SDB Research Laboratory, Takaoka Clinic, Nagoya, Japan in August 2011. Out of 998 patients who agreed to participate in the study, 705 responded to the questionnaire, and 52 questionnaires were excluded because of missing data. Thus, 653 valid questionnaires were used for the analysis.

\section{Instrument development}

The conceptual framework used for the development of CSESA-J was a self-efficacy model based on Bandura's social cognitive theory. ${ }^{16}$ Two conceptual domains are included: self-efficacy and outcome expectancy. Self-efficacy refers to the confidence and ability to self-manage CPAP treatment. Outcome expectancy refers to the self-perceived expectation of benefiting from CPAP treatment. ${ }^{14,15}$

As an item pool of CSESA-J, we used all items on selfefficacy and outcome expectancy from two previous selfefficacy scales for Western sleep apnea patients with CPAP treatment: 18 items from the SEMSA and nine items from the SCT scale. Each original item from the SEMSA and the SCT scale was translated independently from English to Japanese by two translators. The focus group of three experts, one in respiratory medicine and two in nursing, reviewed two translated Japanese versions of items and produced a reconciled Japanese version. The Japanese version was translated back into English by another translator who was not associated with the translation from English to Japanese. The focus group decided on the final Japanese version by comparing the original and back-translated versions. ${ }^{22}$

The group interview of eight Japanese OSA patients treated with CPAP was performed for about 2 hours with four males and four females, aged in years from the $40 \mathrm{~s}$ to the $70 \mathrm{~s}$, who had been receiving CPAP treatment from between 1 month and 10 years. The consensus of opinion among the group of eight Japanese OSA patients treated with CPAP was as follows. Out of 27 items in the Japanese versions of the SEMSA and the SCT scale, four items were determined not be suitable for Japanese OSA patients treated with CPAP. The first item, "If I use CPAP, desire and sexual performance improved" was deemed to be too sensitive a question for a Japanese population. The second item, "If I use CPAP, decrease chance driving accident" would be inappropriate for a Japanese population, as the proportion of those who habitually drive a car is low. The third item, "If I use CPAP then I will not snore" would be selected as one response alternative of "yes" for most Japanese patients. The last item, "If I use CPAP, my partner will sleep better", was deemed to be inappropriate for Japanese OSA patients treated with CPAP, as the proportion of those sleeping in different rooms from their partners is not low. Two other items should be required for slightly modifying the question and the three new items (shown in the "Results" section) were added to the item pool of CSESA-J.

The focus group determined that 23 items of the SEMSA and the SCT scale (excluding the four items above) and the three new items should be used in the survey (described below) according to the consensus of opinion among the group. The decision of the focus group was based on unanimous approval. The focus group added an expert in biostatistics and epidemiology, and reviewed and discussed the items of CSESA-J while considering the summary tables of data from the survey. CSESA-J has 15 items, including nine items from the SEMSA, three items from the SCT scale, and the three new items. The subscales of self-efficacy and outcome expectancy have nine and six items, respectively. Content validity was confirmed by the focus group of four experts. The question for each item was written in Japanese. The responses to each item were graded on a 5-point scale $(1=$ strongly agree, $2=$ moderately agree, $3=$ neutral, $4=$ moderately disagree, and $5=$ strongly disagree).

\section{Survey procedure}

The subjects were asked to complete a self-administered questionnaire in August 2011. The questionnaire included CSESA-J, the Epworth Sleepiness Scale (ESS), ${ }^{23}$ GSES, ${ }^{24}$ and "Self-efficacy scale on health behavior in patients 
with chronic disease." ${ }^{25}$ The ESS is a measure of daytime sleepiness, and is an eight-item, self-administered questionnaire. The Japanese version of GSES, which is a measure of self-efficacy in general daily life, consists of 15 self-administered questions. "Self-efficacy scale of health behavior in patients with chronic disease" aims to assess the self-efficacy of patients with chronic disease. This scale consists of two domains: active coping behavior with diseases and controllability for health. The scale has 24 items.

Height and weight were measured at the starting date of CPAP treatment, and the apnea-hypopnea index (AHI) before CPAP treatment was obtained from clinical records at SDB Research Laboratory, Takaoka Clinic. Body mass index (BMI) was calculated as weight divided by the square of height $\left(\mathrm{kg} / \mathrm{m}^{2}\right)$. The AHI before CPAP treatment was based on overnight polysomnographic recordings made using the Embla N7000 (Natus Medical Incorporated, San Carlos, CA, USA). Sleep stages and respiratory events were scored using the standard diagnostic criteria of the American Academy of Sleep Medicine and a published criterion by registered polysomnogram technicians. ${ }^{26,27}$ Subjects in this study were OSA patients with AHI $\geq 20$, or with $5 \leq \mathrm{AHI}<20$ and a failed oral appliance. ${ }^{28}$

To examine test-retest reliability in this study, a subset of 200 subjects carried out a follow-up survey. One-hundred and thirty subjects completed CSESA-J for a second time at 10-14 days after the initial measurement of all subjects.

\section{Data analyses}

To confirm the two-factor (self-efficacy and outcome expectancy) structure and to establish construct validity, a confirmatory factor analysis of the 15 items of CSESA-J was performed using promax (oblique) rotation, allowing correlated factors. ${ }^{29,30}$

Cronbach's alpha statistic was employed for evaluating the internal consistency of each of the two subscales of CSESA-J. To examine the construct validity of CSESA-J, the Pearson correlation coefficients between CSESA-J and GSES and between CSESA-J and "Self-efficacy scale on health behavior in patients with chronic disease" were calculated. Test-retest reliability using intraclass correlation coefficients (ICCs) was evaluated between the first and second measurements with CSESA-J. The analyses were performed using SPSS ${ }^{\circledR}$ version 21 for Windows (IBM Corporation, Armonk, NY, USA).

\section{Ethical consideration}

This study was approved in November 2010 by the Ethical Review Board for Epidemiological and Clinical Studies of the Fujita Health University School of Medicine, Aichi, Japan.

\section{Results}

The characteristics of all subjects in this study are shown in Table 1. Six hundred and nineteen male and 34 female patients were analyzed. Patients had a mean (standard deviation) age of 55.4 (11.0) years, a mean BMI equal to $28.4(5.1) \mathrm{kg} / \mathrm{m}^{2}$, and a mean AHI of 55.0 (22.2) events/ hour in the diagnostic sleep study. The mean and range of the treatment period were 1,157 days and 1-3,836 days, respectively, and the mean ESS score assessed after CPAP treatment was 8.4 (4.9).

The items and the factor loadings for the two factors of CSESA-J are shown in Table 2. The three new items obtained in the group interview were: "I would use CPAP even with the prospect that CPAP treatment will be permanent" and "I would use CPAP even if I don't notice any symptoms at all" for the self-efficacy subscale, and "If I use CPAP, it will help prevent health problems such as high blood pressure and heart attacks" for the outcome expectancy subscale. CSESA-J had no items with a greater than $95 \%$ selection for any one response alternative for an individual item. In the items included in the domain of self-efficacy, the loadings of factor 1 were $0.47-0.76$, and the loadings of factor 2 were -0.06 to 0.17 . In the items included in the domain of outcome expectancy, the loadings of factor 2 were $0.41-0.92$, and the loadings of factor 1 were -0.08 to 0.19 .

Cronbach's alpha coefficient was 0.85 for the self-efficacy subscale and 0.89 for the outcome expectancy subscale. The correlation coefficients between CSESA-J and GSES and between CSESA-J and "Self-efficacy scale on health behavior in patients with chronic disease" are shown in Table 3. The subscales of CSESA-J were very weakly correlated with GSES and, in regard to "Self-efficacy scale on health behavior

Table I Subject characteristics $(n=653)$

\begin{tabular}{|c|c|}
\hline Characteristics & Mean (SD) \\
\hline Male/female, number & $619 / 34$ \\
\hline Age, years & $55.4(11.0)$ \\
\hline $\mathrm{BMI}, \mathrm{kg} / \mathrm{m}^{2}$ & $28.4(5.1)$ \\
\hline $\mathrm{AHI}$, events/hour ${ }^{\mathrm{a}}$ & $55.0(22.2)$ \\
\hline Treatment period, days & $\mathrm{I}, 157(\mathrm{I}, 125)$ \\
\hline ESS score ${ }^{b}$ & $8.4(4.9)$ \\
\hline GSES score & $43.8(9.6)$ \\
\hline \multicolumn{2}{|c|}{$\begin{array}{l}\text { Self-efficacy scale on health behavior in patients with chronic } \\
\text { disease score }\end{array}$} \\
\hline Scale & $88.6(12.2)$ \\
\hline Subscale of active coping behavior with disease & $54.5(8.4)$ \\
\hline Subscale of controllability for health & $34.1(6.3)$ \\
\hline
\end{tabular}


Table 2 Factor loadings in the rotated-factor matrix for CSESA-J $(\mathrm{n}=653)$

\begin{tabular}{|c|c|c|}
\hline \multirow[t]{2}{*}{ Items } & \multicolumn{2}{|c|}{ Factor } \\
\hline & $\mathbf{I}$ & 2 \\
\hline \multicolumn{3}{|l|}{ Subscale of self-efficacy } \\
\hline $\begin{array}{l}\text { I am confident I would use CPAP regularly, even if I } \\
\text { experience uncomfortable side effects. }\end{array}$ & 0.47 & 0.17 \\
\hline I would use CPAP even if it is troublesome. & 0.67 & 0.10 \\
\hline I would use CPAP even if it were a bother. & 0.74 & -0.02 \\
\hline I would use CPAP even if it made me feel claustrophobic. & 0.64 & 0.05 \\
\hline $\begin{array}{l}\text { I would use CPAP even if it made me take longer } \\
\text { to get ready for bed. }\end{array}$ & 0.72 & 0.00 \\
\hline I would use CPAP even if I had to pay for some of its cost. & 0.62 & 0.11 \\
\hline I would use CPAP even if it disturbed my partner. & 0.68 & -0.01 \\
\hline $\begin{array}{l}\text { I would use CPAP even with the prospect that CPAP } \\
\text { treatment will be permanent. }\end{array}$ & 0.76 & 0.03 \\
\hline $\begin{array}{l}\text { I would use CPAP even if I don't notice any } \\
\text { symptoms at all. }\end{array}$ & 0.65 & -0.06 \\
\hline \multicolumn{3}{|l|}{ Subscale of outcome expectancy } \\
\hline If I use CPAP, I will feel less sleepy during the day. & -0.01 & 0.64 \\
\hline If I use CPAP, my ability to concentrate will improve. & -0.08 & 0.92 \\
\hline If I use CPAP, I will be more active. & 0.00 & 0.83 \\
\hline If I use CPAP, my relationships will improve. & 0.04 & 0.59 \\
\hline If I use CPAP, I will feel better. & 0.12 & 0.66 \\
\hline $\begin{array}{l}\text { If I use CPAP, it will help prevent health problems } \\
\text { such as high blood pressure and heart attacks. }\end{array}$ & 0.19 & $0.4 \mathrm{I}$ \\
\hline
\end{tabular}

Abbreviations: CSESA-J, CPAP Self-Efficacy Questionnaire for Sleep Apnea in Japanese; CPAP, continuous positive airway pressure.

in patients with chronic disease", weakly correlated with the subscale of controllability for health and strongly correlated with the subscale of active coping behavior with disease.

ICCs calculated using data from the first and second measurements with CSESA-J for a subset of 130 subjects are shown in Table 4. The ICC was 0.93 for the self-efficacy and outcome expectancy subscales.

Table 3 Correlation coefficients between CSESA-J and GSES, and "Self-efficacy scale on health behavior in patients with chronic disease" ( $n=653)$

\begin{tabular}{lll}
\hline & \multicolumn{1}{c}{ CSESA-J } & \\
\cline { 2 - 3 } & $\begin{array}{l}\text { Self- } \\
\text { efficacy }\end{array}$ & $\begin{array}{l}\text { Outcome } \\
\text { expectancy }\end{array}$ \\
\hline $\begin{array}{l}\text { Mean score (SD) } \\
\text { Correlation coefficients }\end{array}$ & $34.5(6.3)$ & $21.7(3.9)$ \\
$\begin{array}{l}\text { GSES } \\
\text { Self-efficacy scale on health behavior in patients } \\
\text { with chronic disease }\end{array}$ & $0.09^{* *}$ & $0.10^{* *}$ \\
$\begin{array}{l}\text { Scale } \\
\text { Subscale of active coping behavior }\end{array}$ & $0.72^{* *}$ & $0.75^{* *}$ \\
$\begin{array}{l}\text { with disease } \\
\text { Subscale of controllability for health }\end{array}$ & $0.27^{* *}$ & $0.85^{* *}$ \\
\hline
\end{tabular}

Note: $* * P<0.01$.

Abbreviations: CSESA-J, CPAP Self-Efficacy Questionnaire for Sleep Apnea in Japanese; CPAP, continuous positive airway pressure; GSES, General Self-Efficacy Scale; SD, standard deviation.
Table 4 First and second measurements with CSESA-J $(n=130)$

\begin{tabular}{lll}
\hline & \multicolumn{2}{c}{ CSESA-J } \\
\cline { 2 - 3 } & $\begin{array}{l}\text { Self- } \\
\text { efficacy }\end{array}$ & $\begin{array}{l}\text { Outcome } \\
\text { expectancy }\end{array}$ \\
\hline Mean score (SD) & $35.8(6.2)$ & $21.8(4.4)$ \\
First measurement & $36.0(6.4)$ & $22.1(4.5)$ \\
Second measurement & $0.93 * *$ & $0.93 * *$ \\
Intraclass correlation coefficient between & & \\
the first and second measurements & & \\
\hline Note: $*$ *P $<0.0$ I. & & \\
Abbreviations: CSESA-J, CPAP Self-Efficacy Questionnaire for Sleep Apnea in \\
Japanese; CPAP, continuous positive airway pressure; SD, standard deviation.
\end{tabular}

We developed a new self-efficacy instrument for Japanese OSA patients receiving CPAP treatment. Although the SEMSA and the SCT scale have been used for Western sleep apnea patients treated with CPAP, ${ }^{14,15}$ we judged that these scales would not be suitable for Japanese patients during the planning stage of the present study. In fact, the group interview of Japanese OSA patients treated with CPAP indicated that four items of these scales would not be suitable for Japanese patients. As mentioned above, it was decided that "If I use CPAP, desire and sexual performance improved" would be too sensitive a question for Japanese patients, and "If I use CPAP, decrease the chance of a driving accident" would be inappropriate for a Japanese population, as the proportion of those who habitually drive a car is low. These suggestions from the group interview might be associated with Japanese culture. Following the group interview, the focus group of four experts judged that CSESA-J should include the following additional items: "I would use CPAP even with the prospect that CPAP treatment will be permanent"; "I would use CPAP even if I don't notice any symptoms at all"; and "If I use CPAP, it will help prevent health problems such as high blood pressure and heart attacks". We considered this judgment appropriate, because CPAP treatment can be necessary long term and can possibly reduce the risks of high blood pressure and heart attacks. ${ }^{7}$

CSESA-J consists of two domains, self-efficacy and outcome expectancy, based on Bandura's social cognitive model. ${ }^{16}$ The SEMSA has three domains and the SCT scale has four domains based on Bandura's social cognitive model..$^{14,15}$ The domains in common between the SEMSA and the SCT scale were indicated to be self-efficacy and outcome expectancy, ${ }^{15}$ which are equivalent to the domains included in CSESA-J. The concepts of self-efficacy and outcome expectancy in Bandura's social cognitive model are primary and easily measurable. ${ }^{31,32}$ CSESA-J has 15 items. The number of items on 
the domains of self-efficacy and outcome expectancy is 18 in the SEMSA and nine in the SCT scale. There are no sensitive or difficult questions in CSESA-J for Japanese OSA patients treated with CPAP, and it would take only 5-10 minutes to answer CSESA-J questions. We believe that CSESA-J can be used in clinical research and practice.

Confirmatory factor analysis showed that the two-factor structure of CSESA-J reflected the a priori subscales of self-efficacy and outcome expectancy of the scale. The results of Cronbach's alpha coefficient and ICCs indicated that each subscale of CSESA-J had acceptable internal consistency and sufficient test-retest reliability. The subscales of CSESA-J were strongly correlated with the subscale of active coping behavior with disease of "Self-efficacy scale on health behavior in patients with chronic disease," while they were weakly correlated with GSES and the subscale of controllability for health of "Self-efficacy scale on health behavior in patients with chronic disease." 24,25 "Selfefficacy scale on health behavior in patients with chronic disease" has been used in Japanese patients with chronic diseases such as hypertension, diabetes mellitus, and heart disease. ${ }^{33-35}$ The subscale of active coping behavior with disease reflects confidence and ability to self-manage treatment with exercise, diet, and drugs, while the subscale of controllability for health and GSES have no items regarding particular treatments. The subscales of CSESA-J are specific to CPAP treatment for OSA patients. Thus, the results of our correlation analysis corresponded to the contents of the scales and subscales on GSES and "Self-efficacy scale on health behavior in patients with chronic disease" and suggested construct validity of CSESA-J.

There are some problems and limitations in the present study. Our subjects were 653 patients treated in only one clinic in Japan, while previous studies evaluating the SEMSA and the SCT scale included 213 patients treated in three medical institutions and 51 patients treated in one medical institution, respectively. ${ }^{14,15}$ The average AHI before CPAP treatment in our subjects (55.0 events/hour) was within the range of previous studies for Japanese and Western populations. ${ }^{11-15,36,37}$ The average ESS score after CPAP treatment (8.4) was within the normal range. For evaluating the generalizability of CSESA-J, additional study that includes OSA patients from a greater number of medical institutions would be important. The present study did not include many female subjects (34 females). Previous studies of the SEMSA and the SCT scale included 83 and two females, respectively. ${ }^{14,15}$ Although the percentage of females among people with OSA is not high, ${ }^{38,39}$ female OSA patients might have differing self-efficacy compared to males. To confirm validity for female OSA patients, additional study with more female subjects might be necessary.

CSESA-J items were reviewed by a focus group of experts using the results of a group interview and a survey of OSA patients treated with CPAP. The group interview included eight Japanese OSA patients treated with CPAP. Although it has been indicated that a small group interview should be performed in the development stage of a scale in many cases, ${ }^{22}$ gender-specific interview groups comprising a greater number of patients might be useful for further developing CEASA-J. Some item questions would have unspecified contents, such as uncomfortable side effects as with the SCT scale. ${ }^{14}$ Further review and improvement of CSESA-J questions may well be important.

The present study was cross-sectional. Longitudinal study for evaluating reproducibility over a long period and sensitivity to actual self-efficacy change in CSESA-J is warranted. ${ }^{40,41}$ We did not consider particular factors, such as past experiences of OSA treatment, particular interventions for improving self-efficacy, and CPAP treatment adherence of OSA patients. For measuring intervention effects, changing some CSESA-J items may be important. ${ }^{15,42}$ The subscales of self-efficacy and outcome expectancy of CSESA-J are not equivalent to those of the SEMSA and the SCT scale. Cross-cultural study comparing Japanese and Western OSA patients treated with CPAP would require development of another instrument. ${ }^{43}$

\section{Conclusion}

Our results support CSESA-J as a reliable and valid instrument for measuring self-efficacy of Japanese OSA patients treated with CPAP. Further studies are warranted to confirm validity for female OSA patients and generalizability.

\section{Acknowledgments}

The authors wish to acknowledge the support of the staff and polysomnography technologists at the SDB Research Laboratory, Takaoka Clinic. The study was conducted at the SDB Research Laboratory, Takaoka Clinic, Nagoya, Japan.

\section{Disclosure}

The authors report no conflicts of interest in this work.

\section{References}

1. Young T, Palta M, Dempsey J, Skatrud J, Weber S, Badr S. The occurrence of sleep-disordered breathing among middle-aged adults. N Engl J Med. 1993;328(17):1230-1235.

2. Peppard PE, Young T, Palta M, Skatrud J. Prospective study of the association between sleep-disordered breathing and hypertension. N Engl J Med. 2000;342(19):1378-1384. 
3. Shahar E, Whitney CW, Redline S, et al. Sleep-disordered breathing and cardiovascular disease: cross-sectional results of the Sleep Heart Health Study. Am J Respir Crit Care Med. 2001;163:19-25.

4. Punjabi NM. The epidemiology of adult obstructive sleep apnea. Proc Am Thorac Soc. 2008;5(1):136-143.

5. Giles TL, Lasserson TJ, Smith BJ, Wright J, White J, Cates CJ. Continuous positive airways pressure for obstructive sleep apnoea in adults. Cochrane Database Syst Rev. 2006;(3):CD001106.

6. Barnes M, McEvoy RD, Banks S, et al. Efficacy of positive airway pressure and oral appliance in mild to moderate obstructive sleep apnea. Am J Respir Crit Care Med. 2004;170:656-664.

7. Marin JM, Carrizo SJ, Vicente E, Agusti AG. Long-term cardiovascular outcomes in men with obstructive sleep apnoea-hypopnoea with or without treatment with continuous positive airway pressure: an observational study. Lancet. 2005;365(9464):1046-1053.

8. Albarrak M, Banno K, Sabbagh AA, et al. Utilization of healthcare resources in obstructive sleep apnea syndrome: a 5-year follow-up study in men using CPAP. Sleep. 2005;28(10):1306-1311.

9. Kribbs NB, Pack AI, Kline LR, et al. Objective measurement of patterns of nasal CPAP use by patients with obstructive sleep apnea. Am Rev Respir Dis. 1993;147:887-895.

10. Richards D, Bartlett DJ, Wong K, Malouff J, Grunstein RR. Increased adherence to CPAP with a group cognitive behavioral treatment intervention: a randomized trial. Sleep. 2007;30(5):635-640.

11. Sano N, Sano S, Kataoka M, et al. [Objective evaluation of continuous positive airway pressure (CPAP) compliance in obstructive sleep apnea syndrome (OSAS)]. Jikei J Chest Dis. 2004;16(3):43-48. Japanese.

12. Takaki Y, Yamashiro Y, Nakata K. [Adverse effects and adherence to nasal continuous positive airway pressure in patients with obstructive sleep apnea hypopnea syndrome]. Nihon Kokyuki Gakkai Zasshi. 2004;42(2):127-131. Japanese.

13. Tezuka D, Suzuki J, Haraguchi G, et al. Clinical background of withdrawal continuous positive airway pressure in 61 consecutive cases induced by the therapy. J Adapt Med. 2011;14(2):68-73.

14. Stepnowsky CJ Jr, Marler MR, Ancoli-Israel S. Determinants of nasal CPAP compliance. Sleep Med. 2002;3:239-247.

15. Weaver TE, Maislin G, Dinges DF, et al. Self-efficacy in sleep apnea: instrument development and patient perceptions of obstructive sleep apnea risk, treatment benefit, and volition to use continuous positive airway pressure. Sleep. 2003;26(6):727-732.

16. Bandura A. Self-efficacy: toward a unifying theory of behavioral change. Psychol Rev. 1977;84(2):191-215.

17. Stepnowsky CJ, Palau JJ, Gifford AL, Ancoli-Israel S. A self-management approach to improving continuous positive airway pressure adherence and outcomes. Behav Sleep Med. 2007;5:131-146.

18. Olsen S, Smith S, Oei T, Douglas J. Health belief model predicts adherence to CPAP before experience with CPAP. Eur Respir J. 2008;32: 710-717.

19. Olsen S, Smith S, Oei TP. Adherence to continuous positive airway pressure therapy in obstructive sleep apnoea sufferers: a theoretical approach to treatment adherence and intervention. Clin Psychol Rev. 2008;28:1355-1371.

20. Romppel M, Herrmann-Lingen C, Wachter R, et al. A short form of the General Self-Efficacy Scale (GSE-6): development, psychometric properties and validity in an intercultural non-clinical sample and a sample of patients at risk for heart failure. Psychosoc Med. 2013;10:Doc01.

21. Scherbaum CA, Cohen-Charash Y, Kern MJ. Measuring general selfefficacy: a comparison of three measures using item response theory. Educ Psychol Meas. 2006;66:1047-1063.

22. Streiner DL, Norman GR. Health Measurement Scales: A Practical Guide to Their Development and Use. 2nd ed. Oxford: New York; 1995:15-27.

23. Johns MW. A new method for measuring daytime sleepiness: the Epworth sleepiness scale. Sleep. 1991;14(6):540-545.
24. Sakano Y, Tohjoh M. [The General Self-Efficacy Scale (GSES): scale development and validation]. Jpn J Behav Ther. 1986;12(1):73-82. Japanese.

25. Kim W, Shimada H, Sakano Y. [The relationship between self-efficacy on health behavior and stress responses in chronic disease patients]. Jpn J Psychosom Med. 1996;36(6):499-505. Japanese.

26. [No authors listed]. Sleep-related breathing disorders in adults: recommendations for syndrome definition and measurement techniques in clinical research. The Report of an American Academy of Sleep Medicine Task Force. Sleep. 1999;22(5):667-689.

27. Coleman RM, Bliwise DL, Sajben N, Boomkamp A, de Bruyn LM, Dement WC. Daytime sleepiness in patients with periodic movements in sleep. Sleep. 1982;5 Suppl 2:S191-S202.

28. Sasanabe R, Shiomi T, Inoue Y, et al. [Guidelines for the diagnosis, treatment, and cooperation in sleep disordered breathing]. Sleep Medicine Japan. 2008;2(3):271-278. Japanese.

29. Conway JM, Huffcutt AI. A review and evaluation of exploratory factor analysis practices in organizational research. Organizational Research Methods. 2003;6(2):147-168.

30. Ford JK, MacCallum RC, Tait M. The application of exploratory factor analysis in applied psychology: a critical review and analysis. Pers Psychol. 1986;39:291-314.

31. Mohebi S, Azadbakht L, Feizi A, Sharifirad G, Hozori M. Predicting of perceived self efficacy in the amount of macronutrients intake in women with metabolic syndrome - 2012. J Educ Health Promot. 2014;3:21.

32. Wright JA, Adams WG, Laforge RG, Berry D, Friedman R. Assessing parental self-efficacy for obesity prevention related behaviors. Int $J$ Behav Nutr Phys Act. 2014;11:53.

33. Shimotsu S, Sakamoto S, Horikakwa N, Tomitaka S, Sakamoto K, Sakano Y. Development of the Self-Efficacy Scale for Treatment Acceptance (SESTA). Japanese Journal of Behavioral Medicine. 2005;11(1):7-13. Japanese.

34. Mizuno S. Factor associated with self-efficacy and observance of dietary therapy among older adults with type 2 diabetes. Bulletin of Faculty of Nursing, School of Medicine, Nara Medical University. 2011;7:24-31. Japanese.

35. Suzuki S, Furuse M. Correlation between self-efficacy and life style, physical status and social support in patients after percutaneous coronary intervention. Nihon Kangokenkyu Gakkai Zasshi. 2009;32(5):95-103. Japanese.

36. Takasaki Y, Ohta Y, Nishimura M, et al. [Sleep apnea syndrome in Japan: analysis of pathophysiology and nasal continuous positive airway pressure effectiveness]. Nihon Kokyuki Gakkai Zasshi. 1998;36(1): 53-60. Japanese.

37. Chin K. Problems and recent advances in the understanding of obstructive sleep apnea syndrome. Nihon Kokyuki Gakkai Zasshi. 1999;37(3):169-176. Japanese.

38. Strohl KP, Redline S. Recognition of obstructive sleep apnea. Am J Respir Crit Care Med. 1996;154:279-289.

39. Philip P, Dealberto MJ, Dartigues JF, Guilleminault C, Bioulac B. Prevalence and correlates of nocturnal desaturations in a sample of elderly people. J Sleep Res. 1997;6:264-271.

40. Wang ML, Lemon SC, Welch G, Rosal MC. Development and validation of the Lifestyle Self-Efficacy Scale for Latinos with Diabetes (LSESLD). Ethn Dis. 2013;23(4):428-435.

41. Dandavino M, Young M, Gosselin R, Snell L, Bhanji F. Development and validation of a self-efficacy scale for clinical decision-making in general paediatrics. Pediatr Child Health. 2013;18(4):184-188.

42. Sawyer AM, Canamucio A, Moriarty H, Weaver TE, Richards KC, Kuna ST. Do cognitive perceptions influence CPAP use? Patient Educ Couns. 2011;85:85-91.

43. Klassen RM. Optimism and realism: a review of self-efficacy from a cross-cultural perspective. Int J Psychol. 2004;39(3):205-230. 
Nature and Science of Sleep

\section{Publish your work in this journal}

Nature and Science of Sleep is an international, peer-reviewed, open access journal covering all aspects of sleep science and sleep medicine, including the neurophysiology and functions of sleep, the genetics of sleep, sleep and society, biological rhythms, dreaming, sleep disorders and therapy, and strategies to optimize healthy sleep. The journal welcomes ations, case reports and extended reports. The manuscript management system is completely online and includes a very quick and fair peerreview system, which is all easy to use. Visit http://www.dovepress.com/ testimonials.php to read real quotes from published authors.

Submit your manuscript here: http://www.dovepress.com/nature-and-science-of-sleep-journal 